\title{
ARTICLE
}

\section{How shocking: compensating secondary victims for psychiatric injury $^{\dagger}$}

Keith Rix \& Charlie Cory-Wright

Keith Rix is an honorary consultant forensic psychiatrist, Norfolk and Suffolk National Health Service Foundation Trust, and Visiting Professor of Medical Jurisprudence University of Chester, where he is involved with its MSc in Medicolegal Practice. He is an elected Honorary Fellow of the Faculty of Forensic and Legal Medicine of the Royal College of Physicians. Charlie Cory-Wright $\mathbf{Q C}$ is a barrister practising from chambers at 39 Essex Street, London. He specialises in catastrophic injury and clinical negligence claims. He also has a particular interest in secondary victims. He is a former chair of the Personal Injuries Bar Association. Correspondence Professor Keith J. B. Rix, The Fermoy Unit, Queen Elizabeth Hospital, Gayton Road, King's Lynn PE30 4ET, UK. Email: keith.rix@nsft.nhs.uk

\section{Copyright and usage} (C) The Royal College of Psychiatrists 2018

${ }^{\dagger}$ Based on a joint presentation by the authors at The Fifteenth Grange Annual Conference, Ripley Castle, September 2016.

\section{SUMMARY}

When those whom the law terms 'secondary victims' - i.e. the passive and unwilling witnesses of injury, or of the threat of it, to others - seek compensation through the courts for the psychiatric injuries that they have suffered (traditionally but confusingly referred to as 'nervous shock' claims), there would in theory be the potential for a virtually limitless number of claims. For this reason, the courts have developed and apply a number of, to a large extent, arbitrary 'control mechanisms' as floodgates. This article describes these control mechanisms and other relevant law using recent illustrative cases and with particular reference to the assistance that the courts can expect of psychiatrists as to diagnosis and causation.

\section{LEARNING OBJECTIVES}

- Understand the law relating to the compensation of secondary victims for psychiatric injury

- Appreciate the arbitrariness of the application of the law, as demonstrated in particular by recent cases of such claims by secondary victims

- Understand the proper role of (and limits of) expert psychiatric evidence in secondary victim cases, and therefore how best to assist the courts in relation to them

\section{DECLARATION OF INTEREST}

None.

'It seems to me that in this area of the law, the search for principle was called off in Alcock v Chief Constable of South Yorkshire Police [1992] 1 A.C. 310. No one can pretend that the existing law [...] is founded upon principle [...] Consequently your Lordships are now engaged, not in the bold development of principle, but in a practical attempt, under adverse conditions, to preserve the general perception of the law as a system of rules which is fair between one citizen and another.'

Lord Hoffman in White $v$ Chief Constable of South Yorkshire [1992]

A father standing on the pavement witnesses, from a position of safety, but at very close quarters, a terrible car accident, causing horrific injuries and death to his child. He is deeply traumatised and develops post-traumatic stress disorder (PTSD). He can claim damages for personal injury as a secondary victim. A pedestrian standing next to that father witnesses the same events. He too is deeply traumatised and develops PTSD. He cannot claim. The mother of the child, who is hundreds of miles away, hears about the accident by telephone. Some $6 \mathrm{~h}$ later she gets to the hospital and sees her child's body there, after it has been 'cleaned up'. She too is deeply traumatised and develops PTSD. She may possibly have a good claim, but probably not. Is all this just and fair?

Secondary victims seeking to recover damages for psychiatric injuries have to jump over many hurdles, and their lawyers and the expert psychiatric witnesses have to negotiate what has been described as 'an intricate legal maze' (Thomas 2003). This article summarises the complex law relating to the compensation of secondary victims for psychiatric injury. Recent cases are used to illustrate both the rules that apply in this area of the law and the contribution of expert psychiatric evidence to the resolution of these cases. The relevance of psychiatric evidence to causation issues is highlighted. The article concludes with guidance for psychiatrists providing expert evidence to the courts in such cases.

\section{The law}

\section{Primary or secondary victim?}

The Law Commission (1995) has stated:

\begin{abstract}
'The cases display a great deal of confusion as to which categories of plaintiffa should be regarded as primary and which as secondary victims [...] The distinction may be more of a hindrance than a help.'
\end{abstract}

It is indeed a conceptually confusing area and this distinction gives rise to real difficulties in practice. A primary victim - someone who suffers psychiatric injury due to his or her own injury or the threat of injury - can claim on proof of the same and that it was caused by negligence: no more is needed. A secondary victim has a whole separate set of requirements to discharge, as set out below. All this 
contributes to the intricacy of the legal maze, but two definitions given by Lord Oliver in Alcock $v$ Chief Constable of the South Yorkshire Police [1992] are sufficient for present purposes:

- a primary victim is someone "who is involved either mediately or immediately as a participant in an accident'

- a secondary victim is someone who is "no more than a passive and unwilling witness of an injury to another'.

Alcock is the case of the Hillsborough Stadium football ground disaster. Relatives of some of the 96 Liverpool football fans who were crushed to death unsuccessfully sought damages for the psychiatric injuries which they suffered. Each of the claimants had either been present at the stadium, but remote from the terrace where the fatalities occurred, or had witnessed the event live on television or in later news broadcasts.

It should be noted that the claim of a secondary victim is not a derivative. The claim of the secondary victim does not depend on proof that the primary victim suffered physical or psychiatric injury. It may succeed in the absence of the same, so long as the defendant was in breach of a relevant duty to the secondary victim and that victim suffered relevant damage (again, see below).

\section{The historical context}

The jurisprudence relating to psychiatric damage generally, and secondary victim cases in particular, is all judge-made. It exemplifies classically the common law's approach of developing jurisprudence by accretion - an approach which has both the advantages and the disadvantages of flexibility and of the capacity to change to reflect developments in societal attitudes.

This area of the law evolved from cases in the 19th century which were burdened by an understanding of mental ill health fundamentally irreconcilable with the modern understanding. In Coultas $\mathrm{V}$ Victorian Railway Commissioners (1886) the Privy Council held that a nervous or mental shock 'unaccompanied by any actual physical injury' could not attract damages in an action for negligence. In this case it was the negligence of the Melbourne railway crossing keeper that resulted in a near miss as James and Mary Coultas crossed the railway line in their horse-drawn buggy, causing Mary Coultas to suffer 'severe nervous shock'; she suffered a miscarriage and some months of physical illness.

There has been historic mistrust of psychiatric evidence on the part of the courts. As Lord Bridge observed in McLoughlin v O'Brien [1983]:
'For too long earlier generations of judges have regarded psychiatry and psychiatrists with suspicion, if not hostility.'

For a more detailed historical account see Mullany and Handford [2006].

\section{The control mechanisms}

In Alcock, Lord Oliver identified several elements which had been found in the reported cases to be the essential criteria for a successful secondary victim claim, including most fundamentally (as recently emphasised in Liverpool Women's Hospital NHS Foundation Trust v Ronayne [2015], hereafter referred to as Ronayne) that the claimant should have suffered frank psychiatric illness or injury. These have been described as 'control mechanisms' (see Box 1). They are so called because, to quote His Honour Judge Denyer QC in Morgan v Somerset Partnership NHSFT [2016]:

'they are there, quite simply, to prevent the floodgates, to provide the Courts with a degree of control over claims by persons who were not themselves the primary victim of the relevant negligence.'

As Mrs Justice Swift DBE stated in Shorter $v$ Surrey and Sussex Healthcare NHS Trust [2015]:

"in the absence of these "control mechanisms", the number of secondary victims who would be able to bring successful nervous shock claims would be virtually limitless.'

If the application of these control mechanisms results in what seems to be, or is, unfairness, this is recognised by the courts:

\section{BOX 1 The control mechanisms}

- The claimant must have a close tie of love and affection with the person killed, injured or imperilled ('the dearness test')

- The claimant's illness must have resulted from a sudden and unexpected shock to the claimant's nervous system ('the nervous shock test')

- The claimant must have been either personally present at the scene of the incident or witnessed the aftermath shortly afterwards ('the nearness test')

- The claimant must have directly perceived the incident rather than, for example, heard about it from a third person ('the hearing test')

- The injury suffered must have arisen from witnessing the death of, extreme danger to, or injury and discomfort suffered by, the primary victim ('the causation test')

- There must have been a close temporal connection between the incident and the claimant's perception of it ('the temporal test')

- The claimant must have suffered frank psychiatric illness or injury ('the diagnostic test') 
'this is bound to operate arbitrarily in excluding from an entitlement to damages people who are not obviously less deserving of compensation than those who can succeed' (Wild and Wild v Southend University Hospital NHS Foundation Trust [2014]).

However, this does not mean that the courts will not try to be fair. As Lord Justice Ward said in North Glamorgan NHS Trust v Walters [2002]:

'I understand the concern of the Health Authority [...] that the drain on National Health resources having to meet claims of medical negligence is already sufficiently alarming as to not encourage claims being advanced by secondary victims of that clinical negligence. If I had to make the choice between redressing a wrong to an injured claimant and protecting the pocket of negligent defendants for economic reasons, then I would unrepentantly prefer to do justice than to achieve fiscal expediency.'

\section{What is a frank psychiatric illness or injury?}

One of the leading secondary victim cases is that of McLoughlin. It is important to recall its facts, which were extreme (Box 2). As Lord Wilberforce commented, these circumstances were capable of producing an effect going well beyond that of grief and sorrow. The significance of this point lies in the judgment of Lord Bridge in this same case:

\begin{abstract}
'The first hurdle which a plaintiff claiming damages of the kind in question must surmount is to establish that he is suffering not merely grief, distress or any other normal emotion, but a positive psychiatric illness.'
\end{abstract}

\section{As Lord Oliver put it in Alcock:}

'grief, sorrow, deprivation and the necessity for caring for loved ones who have suffered injury or misfortune must, I think, be considered as ordinary and inevitable incidents of life which, regardless of individual susceptibilities, must be sustained without compensation.'

Herein lies the requirement for the courts to be assisted by experts in psychiatry. As Lord Steyn put it in White $v$ Chief Constable of South Yorkshire [1992], the unsuccessful case brought by police officers who had suffered PTSD caused by their experiences in tending primary victims or otherwise dealing with the bodies of primary victims at the Hillsborough Stadium disaster:

'Only recognisable psychiatric harm ranks for consideration. Where the line is to be drawn is a matter for expert psychiatric evidence.'

Although the use of ICD or DSM diagnoses is not strictly speaking essential, the requirement that there should be significant distress and impairment of functioning means that the legal test effectively requires a diagnosis recognisable to the psychiatric profession. (Note that even such a diagnosis will only be sufficient if it is of a condition which satisfies

\section{B0X 2 The McLoughlin case}

'This appeal arises from a very serious and tragic road accident [between two lorries and then a Ford motor car] [...] The appellant's husband, Thomas McLoughlin, and three of her children, George, aged 17, Kathleen, aged 7 and Gillian, nearly 3, were in a Ford motor car: George was driving. A fourth child, Michael, then aged 11, was a passenger in a following motor car driven by Mr. Pilgrim: this car did not become involved in the accident. [...] As a result of the accident, the appellant's husband suffered bruising and shock; George suffered injuries to his head and face, cerebral concussion, fractures of both scapulae and bruising and abrasions; Kathleen suffered concussion, fracture of the right clavicle, bruising, abrasions and shock; Gillian was so seriously injured that she died almost immediately. At the time, the appellant was at her home about two miles away; an hour or so afterwards the accident was reported to her by Mr. Pilgrim, who told her that he thought George was dying, and that he did not know the whereabouts of her husband or the condition of her daughter. He then drove her to Addenbrooke's hospital, Cambridge. There she saw Michael, who told her that Gillian was dead. She was taken down a corridor and through a window she saw Kathleen, crying, with her face cut and begrimed with dirt and oil. She could hear George shouting and screaming. She was taken to her husband who was sitting with his head in his hands. His shirt was hanging off him and he was covered in mud and oil. He saw the appellant and started sobbing. The appellant was then taken to see George. The whole of his left face and left side was covered. He appeared to recognise the appellant and then lapsed into unconsciousness. Finally, the appellant was taken to Kathleen who by now had been cleaned up. The child was too upset to speak and simply clung to her mother.

There can be no doubt that these circumstances, witnessed by the appellant, were distressing in the extreme and were capable of producing an effect going well beyond that of grief and sorrow.'

(McLoughlin v O'Brian [1983] 1 AC 410 (per Lord Wilberforce))

the requisite features in terms of its causation essentially, that it was caused by the shocking nature of the event to which the individual was exposed - see further below). Although 'recognisable' does not mean the same as 'recognised', it is worth noting the approach of the court in Hussain $v$ The Chief Constable of West Mercia Constabulary [2008]:

'A recognised psychiatric illness is one which has been recognised by the psychiatric profession. In general, they are illnesses that are within the ICD.' (our italics)

It is also worth noting the advice of Marshall et al (2012): 
'without a label that is recognisable, a claimant is likely to have an uphill struggle to achieve compensation without a psychiatric condition that will fit one, or more, of the diagnostic descriptions.'

This is illustrated by the case of Rorrison $v$ West Lothian College (1999). The pursuer, in a negligence case, suffered severe anxiety, panic attacks, loss of confidence and loss of self-esteem, identified by a clinical psychologist, but because she 'had not pleaded any disorder that was recognised in DSMIV' and had not been diagnosed by a psychiatrist as suffering from any recognised psychiatric disorder, her case was dismissed.

\section{What is shock?}

As we have already made clear, it is not sufficient to prove the existence of positive psychiatric illness or recognisable psychiatric harm. That illness or harm must have arisen in a particular way. It must have arisen as a result of what the law terms 'nervous shock' (Box 3). The term has been described as unfortunate because at first glance it seems to refer to the actual experience of being shocked (Rix 2011). The courts recognise this:

\begin{abstract}
"The term "nervous shock" can be misleading. It does not mean that the "shock" is the psychiatric injury caused to the claimant; what it means is that the claimant is claiming damages for the psychiatric injury caused by the shocking event' (Shorter $V$ Surrey and Sussex Healthcare NHS Trust [2015]).
\end{abstract}

So the issue is not just as to diagnosis as such, but also as to aetiology and causation.

The essential ingredients are the suddenness of the experience, its horrifying nature and its direct perception through senses such as sight, hearing or touch. 'Shock' here has a specific meaning in law, not dissimilar to the exceptionally threatening or catastrophic nature of the threshold criterion in

\section{BOX 3 The legal concept of 'shock'}

"I understand "shock" in this context means the sudden sensory perception - that is by seeing, hearing or touching of a person, thing or event, which is so distressing that the perception of the phenomenon affronts or insults the claimant's mind and causes recognizable psychiatric illness' (Brennan J in Jaensch v Coffey [1984] 155 CLR 549)

"Shock" in the context of this cause of action involves the sudden appreciation by sight or sound of a horrifying event, which violently agitates the mind. It has yet to include psychiatric illness caused by the accumulation over a period of time or more gradual assaults on the nervous system' (Lord Ackner in Alcock v Chief Constable of South Yorkshire [1992])
PTSD, and its meaning is not the same as the colloquial meaning:

'To describe an event as shocking in common parlance is to use an epithet so devalued that it can embrace a very wide range of circumstances. But the sense in which it is used in the diagnostic criteria for PTSD must carry more than that colloquial meaning' (His Honour Judge Simon Hawkesworth QC in Ward v Leeds Teaching Hospitals NHS Trust [2004]).

An event of which the person has some warning and gradually cumulative events will not satisfy the suddenness criterion. In Sion $v$ Hampstead Health Authority [1994] the claimant failed to recover damages when his son died 14 days after a road traffic accident. He stayed at his son's bedside, he watched his deterioration, he saw him fall into a coma and die. He was witness to a process that continued for some time and, when death occurred, it was not surprising but expected. Likewise, in another unsuccessful case, where a 14-year-old boy died following a road traffic accident, his parents experienced 'a dawning consciousness that they were going to lose him' (Taylorson $\mathrm{V}$ Shieldness Produce Ltd [1994]). In Alcock it was held that nervous shock was yet to include psychiatric illness caused by the accumulation over a period of time of more gradual assaults on the nervous system.

A distressing experience that is not sufficiently horrifying to agitate the mind violently will not satisfy the horrifying criterion. In Ward, where the claimant's daughter died as a result of medical negligence, the judge found that the claimant's descriptions of what she witnessed did not strike him as shocking at the time, although undoubtedly they were distressing. The experience had to be wholly exceptional:

'An event outside the range of human experience does not encompass the death of a loved one in hospital unless accompanied by circumstances which were wholly exceptional in some way so as to shock or horrify.'

Thus, in Ronayne (see further below) the court found that:

'the appearance of Mrs Ronayne on this occasion must have been both alarming and distressing to the Claimant, but it was not in context exceptional and it was not I think horrifying in the sense in which that word has been used in the authorities.'

Furthermore, what is 'horrifying' has to be judged by objective standards and by reference to persons of ordinary susceptibility (Owers v Medway NHS Foundation Trust [2015]). What Mr Ronayne saw was not horrifying by objective standards. 
A similar issue arose in Shorter, where the claimant was a senior sister in neurointensive care. Mrs Justice Swift DBE said:

'I am well aware that the Claimant's professional background gave her an unusual degree of insight into her sister's medical situation. It was suggested that, as a result, she would have been more sensitive to the events $[\ldots]$ and therefore more likely to find them "horrifying". However, it seems to me that it is necessary to be cautious in finding that the Claimant's professional expertise made the sight of Mrs Sharma more "horrifying" than it would have been to a person without that knowledge. I consider that the "event" must be one which would be recognised as "horrifying" by a person of ordinary susceptibility; in other words, by objective standards. After all, certain people would find it more frightening to have no medical knowledge and not to know what was going on; they may feel helpless and isolated. Others may have armed themselves in advance with medical information from the internet which leads them to feel far greater fear than is in fact justified. It would be unfortunate if secondary victims' claims were to become embroiled in debates about an individual claimant's level of medical knowledge and its effects upon whether an "event" should be classified as "horrifying".'

Hearing about the event in a telephone call will not satisfy the direct perception criterion. In Brock v Northampton General Hospital Trust [2014], where the claimant's daughter died as a result of a negligently treated overdose, the claim failed because the claimant said that it was when the telephone call was received that she realised that her daughter was indeed going to die and it is one of the fine distinctions that a telephone call giving bad news cannot found liability to secondary victims'. As established in McLoughlin, shock must come through sight or hearing of the event or of its immediate aftermath.

The frank psychiatric injury element and the nervous shock element go together to form the requirement, first, that the event should be not just sufficiently sudden and shocking but that it should in fact cause the psychiatric injury and, second, that it should do so because of its sudden and shocking nature. The Royal College of Psychiatrists regards the 'shock-induced' requirement as causing serious problems and has observed:

'The requirement to fit the evidence around the concept of whether or not the disorder is "shockinduced" has no scientific or clinical merit. It is simply playing with words' (cited in Law Commission 1998: para. 5.29).

As a matter of analysis, both of us - psychiatrist and lawyer - agree whole-heartedly with this sentiment. However, this is the law.

\section{Proximity}

The law also requires there to be a sufficiently proximate relationship between the tortfeasor, i.e. the person who has caused the wrong, and the secondary victim. Proximity in the law of negligence generally describes the relationship between parties which is necessary in order to found a duty of care owed by one to the other. This explains the failure of a bystander to recover damages when she heard the noise of a fatal motorcycle accident; it was accepted that she had suffered 'nervous shock' but the motorcyclist owed her no duty (Bourhill v Young [1943]). But in secondary victim cases, the term proximity is also used in a different sense to mean physical proximity in time and space to an event. In this sense it operates as one of the control mechanisms. In a secondary victim case, physical proximity to the event is a necessary, but not sufficient, condition of legal proximity.

In Taylor v A. Novo (UK) Limited [2013] a woman was injured at work when shelving fell on her. She suffered an apparently minor head injury and an ankle injury. She attended hospital and was discharged after a day or so. Some 3 weeks later she suddenly collapsed and died as a result of an unexpected pulmonary embolism caused by a deep vein thrombosis attributed to the original injury. This happened in the presence of her daughter, Ms Taylor, who suffered PTSD as a result. The psychiatric evidence was not in issue. There was clearly a relationship of legal proximity between Novo and their employee. However, the Court of Appeal found that there was no such relationship between Novo and her daughter: or, to put it another way, she was not within their contemplation as someone who might suffer damage as a result of its actions. Her claim as a secondary victim failed as a result. That is because she was not present at the scene of her mother's accident at work or any scene that might sensibly be thought to be part of its immediate aftermath. If she had been allowed to recover damages for what happened 3 weeks after her mother's accident, it would logically have followed that she would have been able to recover damages for psychiatric illness even if her mother's death had occurred months, and possibly years, after the accident (assuming she could prove causation); the court considered it unreasonable to stretch so far the concept of proximity to a secondary victim. Thus, the court decided that allowing Ms Taylor to recover damages would extend the scope of liability to secondary victims considerably further than had been done hitherto and the policy reasons articulated by Lord Steyn in White to confine the right of action of secondary victims by means of strict control mechanisms militated against any further substantial extension. 
There is no doubt that, to some, this judgment seeks to draw absurd distinctions: since the shocking event did not take place until 3 weeks after the original tort, why should that delay be taken into account when considering whether the secondary victim shocked by that event has a claim? It can only sensibly be understood if seen through the prism of the requirement for legal proximity. This in itself may by some be thought to raise a question about the application of that requirement to situations such as this. In any event the case is clearly illustrative of the apparently arbitrary way in which the control mechanisms operate.

\section{Reasonable foreseeability and vulnerability}

In Page v Smith [1996] (note that this is a case of psychiatric injury suffered by a primary victim - i.e. as a result of perceived danger to himself) Lord Lloyd specifically defined reasonable foreseeability as a control mechanism. It is thus an inherent control mechanism in the tort of negligence more generally (in the context of duty and remoteness of damage). This means that, in order for there to be a breach of duty, the circumstances must be such that a person of what the law terms 'normal fortitude' or 'ordinary phlegm' might suffer psychiatric injury by shock. In other words, it must have been reasonably foreseeable that a person of normal fortitude would be affected by what occurred. However, this does not mean that someone who is not of normal fortitude or ordinary phlegm (someone with, to adapt a phrase from the law relating to physical injuries, an 'eggshell mind') cannot recover damages (whether as a primary or as a secondary victim):

'once it is established that a person of normal phlegm would suffer psychiatric injury, then the fact that the victim has suffered unusually badly because of previous vulnerability means that the normal "eggshell skull" or "thick skull" rule of remoteness of damage applies, so that the susceptible plaintiff may recover [damages] for the full extent of the illness' (Marshall 2012).

Thus, the person of normal fortitude test is used to establish the threshold in terms of breach. If the threshold is reached, a person who is not of normal fortitude may have a claim, albeit that but for their vulnerability they might not have suffered psychiatric injury - and if they have suffered more injury as a result of their vulnerability their damages are not limited to those which a person of normal fortitude would have been awarded.

\section{Some illustrative cases}

The following cases illustrate further, and develop, some of the points of law and show the relevance, or otherwise, of psychiatric evidence.

\section{North Glamorgan NHS Trust v Walters [2002]}

When he was aged 10 months, Mrs Walters' son became unwell and was admitted to hospital. He was mistakenly diagnosed as suffering from hepatitis A. In fact, he was suffering from acute hepatitis, which led to liver failure. The NHS trust responsible for the relevant hospital admitted that he had not been properly diagnosed or treated and that, if he had been, he would have been given a liver transplant and would probably have lived. In the event, the baby was kept in hospital while various tests were carried out, but was allowed home at weekends. Box 4 sets out the subsequent events that culminated in the baby's death.

The psychiatrists who gave expert evidence agreed that Mrs Walters had suffered a recognised

\section{BOX 4 The Walters case (as summarised by Mrs Justice Smith DBE in Shorter)}

'[Mrs Walters' baby's] condition deteriorated and his parents took him back to hospital. [Mrs Walters] stayed with him there, sleeping in the same room. Two days or so after his readmission, [Mrs Walters] awoke to hear the baby making choking noises in his cot. She saw a blood-like substance and his body was stiff. A nurse told [Mrs Walters] that he was having a fit. He was transferred to the ICU and, shortly afterwards, Mrs Walters was told by a doctor that it was very unlikely that the baby would have any serious damage as a result of the fit. She understood that he might at worse be slightly brain damaged; she did not consider it was life threatening. This information was, in fact, wholly wrong. The baby had suffered a major epileptic seizure leading to a coma and irreparable brain damage. A few hours later, after a CAT scan, [Mrs Walters] was told that there was no damage to her baby's brain, but that he should be transferred to King's Hospital, London for a liver transplant. He was taken there by ambulance later that day and underwent a further CAT scan which showed diffuse brain injury consistent with a profound hypoxic ischaemic insult.

[Mrs Walters] and the baby's father arrived at King's Hospital in the evening. There, she was told by doctors that the baby had suffered severe brain damage as a result of the fit and was on a life support machine. She was told that, if he had a liver transplant, the chances of success were only $50-50$ and he would be severely handicapped. [Mrs Walters] described herself as "numb, panic stricken and terrified" at what she was told. On the following day, she was told that the brain damage was so severe that her son would have no quality of life if he survived. The parents were asked whether or not they felt that it was in their son's interest to continue with life support. They made the decision that life support should be terminated, this was done shortly afterwards and the baby died in [Mrs Walters'] arms.'

(Shorter v Surrey and Sussex Healthcare NHS Trust [2015] 
psychiatric illness, namely pathological grief reaction. They also agreed that, absent the events that she witnessed, experienced and participated in over the period of her son's illness, her pathological grief reaction would not have occurred.

The question for the trial judge was whether what happened was a sudden appreciation by sight or sound of a horrifying event, rather than an accumulation over a period of time of more gradual assaults on the nervous system, and whether it was that sudden appreciation that caused the pathological grief reaction. Judgment was given in Mrs Walters' favour and the defendant hospital appealed.

In the Court of Appeal, judgment was again given in favour of Mrs Walters. Lord Justice Ward found that:

'on the facts of this case there was an inexorable progression from the moment when the fit occurred as a result of the failure of the hospital properly to diagnose and then to treat the baby, the fit causing the brain damage which shortly thereafter made termination of this child's life inevitable and the dreadful climax when the child died in her arms. It is a seamless tale with an obvious beginning and an equally obvious end. It was played out over a period of 36 hours, which for her both at the time and as subsequently recollected was undoubtedly one drawn-out experience.'

This case established the principle that, if the necessary sudden shock is there, it does not prevent recovery of damages that the events themselves were drawn out over $36 \mathrm{~h}$.

This case is also significant in that it is one of probably only two successful 'hospital cases'. Hospitals are in a very particular position in relation to the psychological responses of individuals due to the illnesses or injuries of others even before one gets to the secondary victim issues. The day-to-day work of hospitals involves people who are injured or ill or, in the case of obstetrics, healthy but vulnerable. They go to hospital followed by their loved ones. Normally that will be because of an injury or illness that occurred elsewhere, whether actionable or not. Sometimes it is because of something that happens in hospital that will sometimes be actionable on the part of the primary victim. But it does not follow even then that any secondary victims have a claim too. First, in hospitals the nature of the triggering event - illness/injury (whether or not caused by negligence, clinical or otherwise) - may well be qualitatively different in terms of whether sudden shock is involved: the event itself may not be perceived at all, for example infection, haemorrhage, etc.; and in any case the trigger is less likely to be sudden: more likely gradual onset. Second, it is, bluntly, in the nature of hospital visits that you can expect bad news: you can expect to see drips, monitors and sick people. This is important and often overlooked. The general point is that experiences of this sort in hospital may be deeply distressing or upsetting, and may well give rise in some cases to psychiatric disorder, but they are less likely to be a 'sudden assault on the nervous system' than something shocking that happens in the street or at work. Thus, if the requirements for 'sudden shock' etc. are absent, perhaps inevitably because of the nature of (say) the clinical negligence concerned, then that will indeed make recovery of damages that much harder.

It is for this reason that, contrary to what one might optimistically call popular belief, and notwithstanding that historically some settlements have been achieved without going to trial, there are in fact very few 'hospital cases' in which secondary victims have been successful at trial. One of these was Walters (see above). Another was Tredget v Bexley Health Authority [1994] - where a baby was born alive but the negligence which inflicted the ultimately fatal injuries on the baby took place during labour in front of the father in circumstances described as 'chaos' and 'pandemonium' in the delivery room. Both of these cases clearly involved wholly exceptional facts, which explain their respective outcomes (see the observations of Lord Justice Tomlinson as to Walters in Ronayne, cited below).

\section{Young v MacVean [2015]}

In this case (Box 5) it was held that Mrs Young sustained psychiatric injury, but hers was of the nature of an illness caused by the accumulation over a period of time, albeit a relatively short time, of more gradual assaults on the nervous system. She suffered no shock as a result of seeing the aftermath. She had become worried but worry is not the same as shock. Although she witnessed the aftermath, it was not the aftermath which caused the shock. What caused the shock was what she was told, so there was no direct appreciation of the event through sight or sound.

\section{BOX 5 Young v MacVean [2015]: the facts}

Mrs Young was on her way to meet her son at the gym. She encountered a traffic jam and a diversion. She saw a badly damaged vehicle against a tree. She sensed that someone had died. She felt relief thinking that it could not be her son or daughter as they did not drive. Before she started her class at the gym she heard that a 20-year-old man had been knocked down. She was preoccupied. She started her class and then noticed six missed calls from her daughter. She said that she felt 'scared'. She said that she became 'hysterical' and that she began screaming. She shouted to her friend that she thought that the victim was her son. The police arrived at the gym and told her that her son was dead. She continued screaming and she started shouting. The police drove her home and, in doing so, they went past a badly damaged wall. 
Owers v Medway NHS Foundation Trust, Secretary of State for Health [2015]

Mr Owers witnessed a deterioration in his wife's condition following a stroke which was not diagnosed and treated sufficiently promptly. The psychiatric evidence is set out in Box 6. The court found that the hospital's breach of duty caused his PTSD and that, but for the breach, he would have suffered depression and adjustment disorder in any event. However, his claim was unsuccessful on the basis that although his experience was "very distressing [there] was no sudden appreciation of a "horrifying" event'.

\section{Liverpool Women's Hospital NHS Foundation Trust v Ronayne [2015]}

The details of this case are set out in Box 7. A clinical psychologist called by the claimant diagnosed $\mathrm{Mr}$ Ronayne as suffering from PTSD. A psychiatrist called by the defendant was initially of the opinion that he had suffered no psychiatric disorder, only anger and stress falling short of psychiatric illness, but at the trial maintained that, if his functioning was impaired, the diagnosis was one of a mild adjustment disorder. The trial judge decided that the claimant was not suffering from PTSD. He did not want to label the condition, but said that if he had to do so he would find that it was an adjustment disorder. He found for Mr Ronayne on the basis that he had suffered a frank psychiatric disorder.

The effect of this judgment at first instance in $\mathrm{Mr}$ Ronayne's favour - as it stood - was significantly to extend recovery of damages by secondary victims, in particular in the hospital context. This was because the claim succeeded (a) simply in the context of a psychological reaction (unspecified in terms of diagnosis) to distressing events, (b) absent any sudden and shocking event, and (c) absent any evidential basis for a finding that Mr Ronayne's psychiatric illness was as a result of the sudden shock of that event.

\section{BOX 6 The psychiatric evidence in Owers}

'[H]is emotional response was of shock, horror and helplessness [...] initially he had felt "very scared" when he realised that his wife was having a stroke, and then increasingly frustrated, angry and hopeless at the delay [...] the subsequent days when his wife became so ill that she might have died was a very frightening time for him [...] [he] also was stressed by the uncertainty regarding her prognosis during the subsequent months of rehabilitation.

(Owers v Medway NHS Foundation Trust, Secretary of State for Health [2015])
BOX 7 The Ronayne case: the facts

Mrs Ronayne underwent a hysterectomy. Three days after discharge from the hospital her health rapidly deteriorated due to peritonitis and septicaemia, which were the result of a ruptured colon. Mr Ronayne witnessed his wife, shortly before emergency exploratory surgery, connected to various machines, including drips and monitors. The following day he saw her unconscious, connected to a ventilator and being administered four types of antibiotic intravenously. Her arms, legs and face were very swollen, and he later described her as resembling the 'Michelin Man'. Mrs Ronayne luckily recovered.

(Liverpool Women's Hospital NHS Foundation Trust v Ronayne [2015]

The defendant hospital appealed. The issues on appeal were (a) whether the events concerned were of a nature capable of founding a secondary victim case, i.e. whether they were, in the necessary sense, 'horrifying', and (b) whether in fact the sudden appreciation of that event or those events, i.e. shock, caused the claimant's psychiatric illness. To put it another way, perhaps more pithily: were the events here objectively of a sufficiently sudden and horrifying nature and, if they were, was it in fact that sudden and horrifying nature that caused the illness?

On appeal it was held that the trial judge:

'was wrong to regard the events of this period of probably about 36 hours as, for present purposes, one event. It was not, like Walters, "a seamless tale with an obvious beginning and an equally obvious end." [There] was in my judgment a series of events over a period of time. There was no "inexorable progression" and the Claimant's perception of what he saw on the two critical occasions was in each case conditioned or informed by the information which he had received in advance and by way of preparation.

[...] I do not regard the sight of his wife at about 1700 on 18 July as the obvious beginning of a distinct event. It is nothing like the "assault upon the senses" to which Mrs Walters awoke [...] I regard it as artificial to regard the sight of his wife in her pre-operative condition as constituting the beginning of an event distinct from what had gone before.

[...] I regard it as wholly artificial to describe the sight of his wife in her post-operative condition as the end of a distinct event. It was all part of a continuum.

It follows that this was not in my judgment a case in which there was a sudden appreciation of an event. [There] was a series of events which gave rise to an accumulation during that period of gradual assaults on the Claimant's mind. [A] gradual realisation by the Claimant that his wife's life was in danger in consequence of a mistake made in carrying out the initial operation. At each stage in this sequence of events the Claimant was conditioned for what he was about to perceive [...].

[What] the Claimant saw on these two occasions was not [...] horrifying by objective standards. Both on the first occasion and on the second the appearance 
of the Claimant's wife was as would ordinarily be expected of a person in hospital in the circumstances in which she found herself. What is required in order to found liability is something which is exceptional in nature. [The] appearance of Mrs Ronayne on this occasion must have been both alarming and distressing to the Claimant, but it was not in context exceptional and it was not I think horrifying in the sense in which that word has been used in the authorities. Certainly however it did not lead to a sudden violent agitation of the mind, because the Claimant was prepared to witness a person in a desperate condition and was moreover already extremely angry.'

Lord Justice Tomlinson decided that the claim fell at the first hurdle, so it was unnecessary for the court to decide on the causation issue - i.e. whether the trial judge was justified in finding that it was the appearance of his wife on these two distinct occasions, as opposed to his wife's ill health, which caused the adjustment disorder. However, he felt it right to record that he was very doubtful about the trial judge's conclusion in this regard. He then went on to analyse the expert psychiatric and psychological evidence as to causation in more detail (Box 8). This analysis illustrates the particular challenge for such expert witnesses.

The main problem here is of course that, in theory at least, the court needs to know whether the psychiatric injury was caused simply by the shocking nature of the events, or by other factors, or by some combination. That obviously raises the question of what happens if (as is in reality highly likely in most cases) it is a complex aetiology which is the result of a combination of the shocking nature of events and of other factors as well.

The authorities do not provide any answer to this question, and each case is currently resolved on its own facts and merits. However, one possible answer for the future which seems to us to make sense would be for the law to adopt and apply here the concept of 'material contribution' (familiar in clinical negligence cases when medical science can identify the fact that a tort has caused damage but has insufficient data to identify the extent of that damage). In this event the claimant would recover damages if he or she can show that the sudden shock of the objectively shocking event made a material contribution to his or her psychiatric condition, even where it is impossible to disentangle the strands of the complex aetiology concerned. However, this is simply speculation by us.

\section{Shorter v Surrey and Sussex Healthcare NHS Trust [2015]}

Mrs Shorter brought a claim after her sister died as a result of a negligently managed stroke. She was herself a senior sister working in neurointensive care. She had a number of experiences culminating
B0X 8 The Ronayne case: Lord Justice Tomlinson's causal analysis

'It was [Dr A's] evidence that the Claimant had suffered PTSD, and she did not address the question whether what the judge called this "visceral two day, subjective perception or experience" either could or did cause the diagnostically different condition adjustment disorder. [...]

With respect to the judge, I think he gave insufficient weight to the circumstance that Mr Ronayne was already extremely angry before he saw his wife on the second occasion, which might properly be regarded as the more distressing of the two. [...] Furthermore, having found none of the persistent recurrent flashbacks and/or nightmares that characterise PTSD, the judge should in my judgment have been far less ready to attribute causative potency to the two visual images, rather than to the whole set of circumstances which overcame Mrs Ronayne and the consequential effect upon her husband. It was [Dr B's] uncontradicted evidence that if the Claimant's psychiatric condition were the result of a sudden visceral attack of the type posited by the judge, then one would expect it to manifest itself in intrusive recollection. Lack of intrusive recollection therefore told against the visual images being the trigger of or for the condition.

On the other hand, it was not the evidence of [Dr B] that adjustment disorder could not be caused by sudden exposure to a horrifying image, rather that the presentation of Mr Ronayne and his affect overall was not indicative of a condition which had been so caused and was far more consistent with a condition caused by the entirety of the circumstances in which his wife became unwell.

Had the point been live before us, it may be that the judge's conclusion could be justified on the basis that the

Claimant's experiences on 18 and 19 July played a part in the cause and development of the adjustment disorder, as [Dr B] unsurprisingly accepted to be the case. Had it been necessary to consider the case on this basis however, I would for my part have wanted to give further consideration to the question whether, in a case of adjustment disorder as opposed to PTSD, it is logically defensible to isolate one or two events from a larger continuum in an attempt to attract that liability which attaches to the perception of a tortiously caused horrifying event. As it is, the point does not arise and I need express no concluded view on the question whether causation was in this case made out as the judge thought.'

(Liverpool Women's Hospital NHS Foundation Trust v Ronayne [2015])

in her witnessing her sister's death (Box 9). Her claim was unsuccessful, the trial judge holding that:

'There was a series of events over a period of time [...] However, much of her fear, panic and anxiety were caused by information communicated to her [...] I do not consider that any of the individual events within the series actually witnessed by the Claimant 
BOX 9 The Shorter case: the claimant's experience

1 Advised by her brother-in-law of her sister's sudden deterioration.

2 Saw her sister at the East Surrey Hospital in the knowledge that she had suffered an undiagnosed and therefore untreated subarachnoid haemorrhage and in the knowledge of its likely consequences; she said that she was very frightened and that the deterioration was unexpected.

3 Advised in a telephone call from her brother-in-law of her sister's first seizure on arrival at St George's Hospital.

4 Advised in a telephone call from her brother-in-law of a further seizure at St George's and heard her brother-inlaw's panic and confusion.

5 In day room at St George's her brother-in-law said her sister had 'gone'

6 Saw her sister at St George's and heard her brother-inlaw's panic and confusion; she said it hit her like a sledge-hammer and that she felt sick and horrified.

7 Advised by medical staff that her sister was unlikely to survive.

8 Witnessed her sister's death.

(Shorter v Surrey and Sussex Healthcare NHS Trust

gave rise to the sudden and direct appreciation of a "horrifying event" [...]

[...] Even when she witnessed her sister on the life support machine, her perception was informed by the information she had been receiving [...] and by her own professional knowledge [...] In the circumstances, it does not appear to me that the sight of her can be regarded as a "horrifying event"; nor was it sudden or unexpected [...]

[...] In my view, there was a series of different events on 12/13 May that gave rise to an accumulation during that period of gradual assaults on the Claimant's mind and resulted in her psychiatric illness.'

Like the judgment in Ronayne, this is also a judgment that illustrates the relevance of psychiatric evidence to causation (Box 10). It illustrates the key role of visual experiences such as flashbacks, the need for a forensic analysis of the different accounts that the claimant gives of their experiences, the need to take into account the claimant's reaction, or otherwise, to previous shocking experiences and the reliance placed on observation of the claimant's mental state when giving evidence in court as to their experiences.

\section{Morgan v Somerset Partnership NHSFT [2016]}

On 26 October 2011, Mrs Morgan's husband attempted suicide and was assessed by one of the defendant trust's employees. On 1 November
2011, she had gone to work, she came home and there was a note on the table from her husband indicating that he was going to commit suicide. She went into the garage and found him there. He had cut his wrists. There was a significant amount of blood. He was subsequently taken to hospital; happily, he survived. Mrs Morgan suffered an adjustment disorder consequent on finding her husband in that state. She claimed negligence against the NHS trust whose employee had attended him on 26 October. However, the claim failed; the judge found that there was 'simply not the regular degree of proximity in terms of time and space between the original tort, vis-à-vis the Defendants and the Claimant's husband, the primary victim, and the loss or rather the damage suffered by the Claimant [...] that is necessary in order to get this type of claim off the ground'.

\section{Guidance for psychiatrists providing expert evidence to the courts}

The framework for an assessment of a secondary victim is the same as for any psychiatric medicolegal assessment: history-taking to establish the facts and assumed facts, mental state examination, and consideration of corroborative and documentary evidence as to the facts. This forms the basis for providing an opinion as to diagnosis and, critically in such a case, causation. The key points are set out in Box 11.

With regard to the investigation of the facts and assumed facts, there is considerable overlap with the exercise that will be undertaken by the lawyers and, if the case goes to trial, the judge. Ultimately the judge will decide the facts and what he or she decides may alter the factual basis for the psychiatrist's opinion. However, the psychiatrist has to have an assumed factual basis in order to address issues of diagnosis and causation even if it is necessary later to revise opinions on the basis of a different factual scenario.

Some of the most important facts in the case will usually be the claimant's experiences following the tortious event. It is therefore important, when the claimant is sufficiently settled, carefully to obtain a chronological account of what they experienced, paying attention to what they actually perceived (the event or its components), the suddenness or otherwise of the perception, through what senses (sight, hearing, touch, etc.) the event or component was perceived and whether directly or indirectly, and what effect the perception had on them at the time. The thoughts and feelings, physical (such as autonomic manifestations of anxiety) as well as emotional, may assist as to the extent to which the mind was violently agitated. 


\section{B0X 10 The Shorter case: Mrs Justice Swift's causal analysis}

' $[\mathrm{Dr} \mathrm{C}]$ identified the Claimant's visual experiences, in particular her visual experience at the $\mathrm{A} \& \mathrm{E}$ Department at East Surrey Hospital (ESH), as of the greatest significance in causing her psychiatric disorder. In doing so, he relied on the witness evidence of the Claimant, Mr Sharma and Mr Shorter, on the Claimant's descriptions of "flashbacks" of the scene there and on her distress when giving oral evidence about the relevant events.

However, it is to be noted that, in the Claimant's first account of the events of 12 May 2009, given in October 2011 for the purposes of [Dr C's] Condition and Prognosis Report, there is a reference to the fact that Mrs Sharma "was in a lot of pain" whilst at ESH, but no mention of a distressing scene such as that described in the Claimant's witness statement of July 2013. Furthermore, the only reference to "flashbacks" in that Report was in a GP note dated 30 October 2009, recording that the Claimant had "terrible memories of her sister's death" and "flashbacks" [...] I appreciate of course that the purpose of [Dr C's] first Report was to provide advice on Condition and Prognosis, rather than on Causation. However, if what the Claimant saw on her arrival at the A \& E Department was such an emotionally charged incident and the most important factor in causing her psychiatric condition, one would have expected her to have described the event to $[\mathrm{Dr} \mathrm{C}]$ and him to have included it in his Report.

[Dr C] expressed the view that the Claimant's experiences in the A \& E Department were sufficient to cause her psychiatric disorder, even had Mrs Sharma in the end survived. I must say that I found that a very surprising assertion. Had Mrs Sharma survived, the Claimant would have been spared the grief of her loss, the anger of knowing it need never have happened, the feelings of guilt at not having done more to ensure Mrs Sharma's safety and the distressing experiences which she subsequently had at SGH [St George's Hospital]. She would not have had to undergo the repeated reminders of the events at SGH when at work. Moreover, she had previously witnessed her mother's death, which took place suddenly and was what the Claimant described as "horrific", even for her as a nurse, without sustaining a psychiatric disorder. It seems to me highly unlikely that she would have suffered such a disorder had Mrs Sharma survived.

I found it surprising also that [Dr C] laid comparatively little emphasis on what the Claimant experienced in the ITU at SGH, when seeing her sister on a life support machine brought home to her the reality that she had "lost her". It was an experience which had caused the Claimant considerable distress when speaking of it during her interview with $[\mathrm{Dr} \mathrm{C}]$ in October 2011 and when giving oral evidence. It caused - and continues to cause - regular "flashbacks" in the course of her work. Yet, he appeared to attach significantly less importance to that incident than to her experience in the $A \& E$ Department at ESH.

[Dr D], on the other hand, laid little emphasis on the events at ESH and SGH. He acknowledged that they had played some part in the Claimant's disorder, but considered that, even had she not been present at either the A \& E Department at ESH or the ITU at SGH, she would still have developed a psychiatric disorder of similar duration and severity. That assertion was on the basis that the Claimant would have suffered significant guilt as a result of her failure to be with her sister.

It appeared to me that the stances adopted by the two Consultant Psychiatrists were significantly influenced by their knowledge that, in the case of a "secondary victim" such as the Claimant, visual experiences are key factors in the recovery of damages. Their causation evidence was focussed primarily on the part played by those experiences. Thus, $[\mathrm{Dr} \mathrm{C}]$ asserted that it was the two visual experiences in the Hospitals - and in particular, the first - which were the key incidents. [Dr D] acknowledged that it was not possible to separate the various incidents on 12/13 May, all of which had played a part in causing the Claimant's psychiatric disorder. However, he asserted that the events of least importance were the visual experiences. I did not find either of those stances compelling.

I consider that it is clear, on a balance of probabilities, that the incidents which occurred on 12/13 May all made a contribution to the development of the Claimant's psychiatric disorder. I do not consider that it is realistic to carve up the incidents into those which did and did not play a part. In any event [...]। do not accept that the visual experience which the Claimant had on her arrival at ESH was as dramatic as that described by her. The extent of her distress when giving evidence was much greater when she talked of the journey to, and the time spent at, SGH. That tends to support the fact that those incidents had a greater emotional impact than the time spent in the A \& E Department at ESH.'

(Shorter v Surrey and Sussex Healthcare NHS Trust [2015])
Notwithstanding the historical tendency of some judges to be dismissive of 'psychiatric labels', in this context very careful attention needs to be given to diagnosis. As Lord Justice Tomlinson said in Ronayne, 'Close attention to diagnostic criteria is in my view likely [...] to be of assistance in resolving what are often complex questions of causation'. It will almost always be helpful to refer to a system of classification, such as ICD or DSM, which is familiar to any other experts in the case, but being mindful of the warnings as to reliance on them in the medicolegal context (Box 12).

The necessary causal analysis will be fact specific. The first issue will be whether the court will find that there was an event, or were events, sufficiently shocking or horrifying for it to be foreseeable that a person of 'normal fortitude' or 'ordinary phlegm' would suffer psychiatric injury rather than something no more than deeply distressing or upsetting.
The second issue will be whether the claimant has suffered an identifiable psychiatric injury. The critical issue will be whether there is a connection. By reference, if possible, to psychopathology such as the content of nightmares, flashbacks or other intrusive phenomena, it will be necessary to give an opinion as to whether, on a balance of probabilities, it was the sudden, unexpected and shocking nature of that event, or one or more of its components, that caused the identified psychiatric injury. In the alternative, the opinion may be that it was some other response, such as extreme grief, that caused the psychiatric injury. These are not mutually exclusive scenarios. A claimant may suffer PTSD as a consequence of the nervous shock and a complicated grief reaction which would have occurred even if the claimant had not been exposed to the shocking event or events. The causal analysis may be further complicated by the need to take into account pre-existing 
BOX 11 Guidance for expert psychiatric witnesses in secondary victim cases

- Explore the claimant's reaction to past traumatic experiences

- Explore the claimant's relationship with the primary victim, paying particular attention to close ties of love and affection

- Create a time line and explore experiences, thoughts and feelings step by step, noting any changes in the claimant's mental state as they describe these

- Look for evidence that the perception has been conditioned or informed by information received in advance and by way of preparation

- Identify as far as possible the cause of any shock - the triggering event (taking into account the content of nightmares and intrusive phenomena such as flashbacks)

- Consider whether the triggering event is sufficiently sudden and shocking - an objective test: would it be expected to cause psychiatric injury to a person of 'ordinary phlegm' and 'normal fortitude'?

- Is there a frank psychiatric disorder? If so, what is the diagnosis?

- Ask whether the psychiatric illness can be ascribed (a) to a particular sudden, unexpected and shocking event, and (b) to the sudden, unexpected and shocking nature of that event

- Consider, and if necessary take into account, the possibility that it was some other response, such as extreme grief, that caused the illness

- Be able to 'subtract' what would have occurred if there had been no sudden, horrifying event

vulnerability, adverse events and circumstances coincidental with, or subsequent to, and independent of, the index event and non-tortious aspects of the index event such as, in an obstetric case, the 'ordinary' stress and anxiety associated with childbirth.

\section{Proposals for reform}

The Law Commission put forward proposals for reform in its consultation paper Liability for Psychiatric Illness in 1995. Readers are further referred to Teff (2009), who has suggested that statutory reform is needed to achieve a greater legal coherence and to provide a remedy that reflects the impact and severity of harm but is not restricted to psychiatric harm. He proposes a legal framework rooted in reasonable foreseeability of mental or emotional harm with a liability threshold of 'moderate severity'. He proposes modifications to the compensatory regime for personal injuries to allow for concerns about a proliferation of claims.

\section{BOX 12 Warnings as to reliance on ICD and DSM diagnoses}

'These descriptions and guidelines carry no theoretical implications, and they do not pretend to be comprehensive statements about the current state of knowledge of the disorders. They are simply a set of symptoms and comments that have been agreed, by a large number of advisors and consultants in many different countries, to be a reasonable basis for defining the limits of categories in the classification of mental disorders' (World Health Organization 1992: p. 2).

There are 'risks and limitations' in the use of DSM-5 in forensic settings: 'risks that diagnostic information will be misused or misunderstood [...] because of the imperfect fit between the questions of ultimate concern to the law and the information contained in a clinical diagnosis. In most situations, the clinical diagnosis of a DSM- 5 mental disorder [...] does not imply that an individual with such a condition meets the legal criteria for the presence of a mental disorder or a specified legal standard [...] Diagnostic criteria are offered as guidelines for making diagnoses, and their use should be informed by clinical judgment' (American Psychiatric Association 2013: p. 21)

\section{Conclusions}

The law that governs the compensation of secondary victims for psychiatric injury may not be fair and it may be in need of reform. However, its rules achieve some degree of consistency. Nevertheless, to achieve this, the courts depend on the expertise of psychiatrists. What is required of them is to exercise their ordinary skills of history-taking, mental state examination, diagnosis and differential diagnosis, and aetiological formulation with an understanding of the relevant law.

\section{References}

American Psychiatric Association (2013) Diagnostic and Statistical Manual of Mental Disorders (5th edn) (DSM-5). APA.

Law Commission (1995) Liability for Psychiatric IIIness: A Consultation Paper (LCCP137). TSO (The Stationery Office).

Law Commission (1998) Liability for Psychiatric IIIness (Report LC249). TSO (The Stationery Office).

*Marshall D, Kennedy J, Azib R (2012) Litigating Psychiatric Injury Claims. Bloomsbury.

*Mullany NJ, Handford P (2006) Mullany \& Handford's Tort Liability for Psychiatric Damage (2nd edn) Law Book Company of Australasia.

Rix KJB (2011) Expert Psychiatric Evidence. RCPsych Publications.

*Teff H (2009) Causing Psychiatric and Emotional Harm: Reshaping the Boundaries of Legal Liability. Hart Publishing.

Thomas C (2003) Psychiatric injury (1). Solicitors Journal, 147: 489-91.

World Health Organization (1992) The ICD-10 Classification of Mental and Behavioural Disorders (ICD-10). WHO.
MCO answers

1 c 2 b 3 b 4 d 5 a 


\section{Cases}

Alcock v Chief Constable of the South Yorkshire Police [1992] 1 AC 310.

Bourhill $v$ Young [1943] AC 92.

Brock v Northampton General Hospital Trust [2014] EWHC 4244 OB.

Coultas v Victorian Railway Commissioners (1886) 12 VLR 895.

Frost (White) v Chief Constable of South Yorkshire [1992] 2 AC 455.

Hussain v The Chief Constable of West Mercia Constabulary [2008] EWCA Civ 1205.

Jaensch v Coffey [1984] 155 CLR 549.

Liverpool Women's Hospital NHS Foundation Trust v Ronayne [2015] EWCA Civ 588.

McLoughlin v O'Brien [1983] 1 AC 410.

Morgan v Somerset Partnership NHSFT [2016] WL 01745157.

North Glamorgan NHS Trust v Walters [2002] EWCA Civ 1792.

Owers v Medway NHS Foundation Trust [2015] EWCA Civ 588.
Page v Smith [1996] AC 155

Rorrison v West Lothian College (1999) Rep LR 102

Shorter v Surrey and Sussex Healthcare NHS Trust [2015] EWHC 614 (OB).

Sion v Hampstead Health Authority [1994] 5 Med LR 170.

Taylor v A. Novo (UK) Limited [2013] EWCA Civ 194.

Taylorson v Shieldness Produce Ltd [1994] PIOR P329.

Tredget $v$ Bexley Health Authority [1994] 5 Medical LR 178.

Ward $v$ Leeds Teaching Hospitals NHS Trust [2004] EWHC 2106 (QB).

White v Chief Constable of South Yorkshire [1992] 2 AC 455.

Wild and Wild $v$ Southend University Hospital NHS Foundation Trust [2014] EWHC 4053 (QB).

Young $v$ MacVean [2015] CSIH 70

* Suggested further reading.

\section{MCOs}

Select the single best option for each question stem

1 The law relating to the compensation of secondary victims for psychiatric injury:

$a$ is founded on principle

b achieves fairness between one citizen and another

c is an intricate legal maze

d allowed the relatives of some of the 96 Liverpool football fans crushed to death in the Hillsborough Stadium football ground disaster to recover damages for the psychiatric injuries they suffered

e was created by the Law Commission in 1995.

\section{A secondary victim in law is:}

a a person who is involved mediately or immediately as a participant of an accident

b a person who is no more than a passive and unwilling witness of injury, or threat thereof, to another

c exempt from satisfying the control mechanisms

d someone whose perception of a traumatic event is mediated indirectly by a medium such as the telephone or a televised transmitted image e a defendant health authority that has to meet a claim for medical negligence.

3 The control mechanisms:

a do not apply to secondary victim cases

b operate arbitrarily in excluding from an entitlement to damages people who are not obviously less deserving of compensation than those who can succeed

c provide the courts with no control over claims by persons who were not themselves the primary victim of the relevant negligence

d provide for a claimant's perception of an incident through the medium of a third person

e do not apply in 'hospital cases'.

\section{Nervous shock:}

a is synonymous with post-traumatic stress disorder

b equates with grief, distress or any other normal emotion

c equates with the psychiatric injury caused to the claimant

d means that the claimant is claiming damages for the psychiatric injury caused by the shocking event e refers to the subjective aspects of the claimant's experience.

5 In secondary victim cases, expert psychiatric evidence:

a is required to draw the line where recognisable psychiatric harm ranks for consideration

b does not need to involve close attention to diagnostic criteria, as the courts are not interested in psychiatric 'labels'

c is determinative of the issue of whether an event was sufficiently horrifying to agitate the mind violently

d should avoid complex issues of causation, as these are matters for the court

e should avoid reference to classificatory systems such as ICD and DSM. 